This document is the accepted manuscript version of the following article:

Hersperger, A. M., \& Fertner, C. (2020). Digital plans and plan data in planning support science.

Environment and Planning B: Urban Analytics and City Science. https://doi.org/10.1177/2399808320983002

\title{
Commentary
}

\section{Digital plans and plan data in planning support science}

Commentary on Stan Geertman and John Stillwell's article on "Planning support science: Developments and challenges" Environment and Planning B: Urban Analytics and City Science 47: 1326-1342.

\section{Authors:}

Anna M. Hersperger, Land Change Science, Swiss Federal Research Institute WSL, Switzerland Christian Fertner, Department of Geosciences and Natural Resource Management, University of Copenhagen.

\section{Corresponding author:}

Anna M. Hersperger, Head of Land use Systems Group, Swiss Federal Research Institute WSL, Zürcherstrasse 111, 8903 Birmensdorf, Switzerland

anna.hersperger@wsl.ch

Phone: ++41447392515 


\section{Digital plans and plan data in planning support science}

We comment on the article by Stan Geertman and John Stillwell titled "Planning support science: Developments and challenges" published in Volume 47 issue 8 in Environment and Planning B: Urban Analytics and City Science. In this article, Geertman and Stillwell promote the Planning Support Science (PPScience), based on their observation that a fundamental transformation is taking place wherein the field of planning support systems PSS is maturing into an own science (Geertman and Stillwell 2020c, see also 2020a). Indeed, planning support systems are proliferating, due to digitization, big data, smart cities and open data, among others, which creates new opportunities for PSS and their integration into urban management.

Geertman and Stillwell present PSScience as rooted in three interconnected dimensions situated in their respective spatial, temporal, environmental and socio-political contexts (Figure 1 in Geertman and Stillwell 2020c). These dimensions are: (1) the application dimension, referring to the goal of PSScience to support sustainable and resilience urban futures and possibility to address a broad range of applications and knowledge fields; (2) the governance dimension, which concerns the processorientation of PSScience, framed chiefly as collaborative planning; and (3) the instrumentation dimension, including information and communication technology and planning support systems. Furthermore, PSScience is described as intrinsically context specific, so that one planning support system cannot be used within a different context without adaptation.

While we support the idea that the research field of planning support systems should develop into a planning support science, we note that in the current debate the rapidly progressing digitization in 
spatial planning practice is insufficiently taken into account. In particular, digital plans and plan data are not mentioned in Geertman and Stillwell's paper. This is likely caused by the fact that the authors narrowly focus on collaborative planning that tends to stress interactions rather than plans. However, planning is multifaceted and plans play a key role in many planning activities. Our commentary thus looks at the potential role of digital plans and related planning data for PSScience. We first point out the position of plans and plan data in planning activities and then address the current status of digitalization in spatial planning before we conclude with three expectations for the further development of the PSS from a planning perspective.

\section{Plans and plan data in multifaceted planning activities}

Geertman \& Stillwell address the planning process within the governance dimension. Based on a brief review of the development of planning in recent decades and the associated changes in the role of information, knowledge, and instruments Geertman \& Stillwell put collaborative planning in focus of PPScience. This approach to planning is based on the so-called communicative turn in planning (Healey, 1996), which is process-oriented, embracing a wide diversity of actors and their knowledge and values. While this approach to planning is certainly common, for example in community development and vision building, statutory planning with a strong focus on plans (land use plans, zoning) remains prominent in contemporary planning practice. In many countries statutory planning, for example, defines a minimum of participation, ensures conformance between different planning authorities and is the legal basis for future development. Indeed, statutory planning is a core area of planning and an important part of the everyday life of planning practitioners. We thus regard it as a lost opportunity for PPScience to focus exclusively on collaborative planning processes.

In contrast to Geertman and Stillwell we therefore propose to conceptualize planning broadly, including collaborative planning processes as well as regulative activities. The origin of PSS in envisioning the impact of alternative scenarios to develop planning proposal is very important, but the processes in the 
legal planning systems and regulative activities must not be overlooked. They are characterized by elements such as plan drafting, public hearing, plan adoption procedures, periods of legal effectiveness, reassessment and plan amendment. These processes and activities and the resulting plans hold a key role in spatial planning.

\section{Digitalization and planning support in planning practice}

Geertman and Stillwell describe a PSS implementation gap, where the adoption of PSS in practice has not been as widespread as the developer community might have hoped for (Geertman 2017, Geertman and Stillwell 2020a, 2020c). Multiple reasons have been identified for this gap, including an insufficient attention to contextual factors such as political, planning and policy contexts in many PSSs (Geertman and Stillwell 2020b).

However, when we look at the everyday planning practice, various PSS are in use. They are contextspecific in a way that they are adapted to e.g. local planning authorities within a given planning system (state/country). These PSS usually do not provide specific scenario or design tools, but support internal processes, external communication as well as parts of the formal planning process. Thus many have elements of all three PSS categories according to Vonk et al.'s (2006) definition, i.e. provision of information, support of communication processes, and facilitation of analysis, modelling and design.

Following that, many planning authorities are offering a range of planning related services digitally (ESPON 2018) and we can see the increasing digitization of the formal processes and of the plans themselves. Important backbones of this development are digital plan registers and databases, which got systematically established in the planning systems of many countries in the past years (Fertner et al. 2019). These databases contain geodata, which mirror parts of or the whole plan and sometimes are even the actual legally binding regulation, and can be accessed over internal and public portals or also third party software. These developments provide significant new opportunities for PSScience, both regarding the digitization of processes and the digitization of plans. 
This close look shows that digitization and PSS are present in planning practice and that, from a practice perspective, the implementation gap might not be so severe. It further supports our proposition that the future development of PSScience could benefit from conceptualizing planning broadly. As Klosterman (1997) pointed out, the appropriate role of technology in planning support must begin with a conception of planning: An encompassing conception of planning would thus allow PSScience to cover a broad field.

Digitization in planning is on a fast track. This opens new opportunities and also new obligations for planning authorities, such as the requirement to provide all plans (in all version) in digital form, to use standardized data models, and make digital plans accessible on central portals/platforms, within a planning system and beyond (e.g. INSPIRE). The advancement of digitization is also expected to increase planners' affinity for working in the digital environment and eventually with PSS.

\section{Conclusions}

We conclude with three expectations for the further development of PSS from a planning perspective:

- PSScience can best be developed in close cooperation with a broad spectrum of planning practitioners;

- PSScience should specifically focus on the interfaces to the geoportals and data standards used in institutionalized digitized planning;

- PPScience could make a major contribution to improving planning in countries with limited resources by developing tools for enriching basic functions like registration of and public access to planning information with open geospatial data.

If this is taken into account, digital plans and plan data can play a key role in the development of the intended planning support science and assist to overcome the repeatedly emphasized implementation gap. 


\section{References:}

Fertner C, Aagaard Christensen A, Andersen PS et al (2019) Emerging digital plan data - new research perspectives on planning practice and evaluation. Geografisk Tidsskrift-Danish Journal of Geography 119(1):6-16

Geertman S (2017) PSS: Beyond the implementation gap. Transportation Research Part A: Policy and Practice 104:70-76

Geertman S, Stillwell J (eds) (2020a) The handbook of planning support science. Edward Elgar, Cheltenham

Geertman S, Stillwell J (2020b) Planning support science: challenges, themes and applications. In: Geertman S. andStillwell J. (eds), The handbook of planning support science. Edward Elgar, Cheltenham, pp. 1-19

Geertman S, Stillwell J (2020c) Planning support science: Developments and challenges. Environment and Planning B: Urban Analytics and City Science 47(8):1326-1342

Healey P, Khakee A, Motte A, Needham B (1997) Making strategic spatial plans. Innovation in Europe. UCL Press, London

Klosterman RE (1997) Planning Support Systems: A New Perspective on Computer-Aided Planning. Journal of Planning Education and Research 17(1):45-54

Vonk G, Geertman S, Schot P (2006) Usage of planning support systems. In: van Leeuwen J. andTimmermans H. (eds), Innovations in design and decision support systems in architecture and urban planning. Springer, Berlin, pp. 263-274 